\title{
Research and Development of Electric Energy Efficiency Management Experiment System
}

\author{
Songxue $\mathrm{Hou}^{1}$, Wei Wu ${ }^{2}$, Shunchao Wang ${ }^{3}, \mathrm{Yu} \mathrm{Hu}^{4}$, Ming Fa ${ }^{5}$ \\ ${ }^{1}$ Technical Training Center of Hubei Electric Power Company, Wuhan 430079 \\ ${ }^{2}$ Hubei Electric Power Company, Wuhan 430071 \\ ${ }^{3}$ Customer Service Center of Hubei Electric Power Company, Wuhan 430071 \\ ${ }^{4}$ Hubei Xiaogan Power Supply Company 432900
}

Keyword: electric energy efficiency management; experiment system; energy conservation and emissions reduction; case analysis; simulation

\begin{abstract}
The research and development of the electric energy efficiency management experiment system aims at elevating the related technology and management level of energy efficiency in Hubei Electric Power Company by means of constructing the electric energy efficiency management experiment system. In this paper, the necessity of electric energy efficiency management experiment system construction is described in the first place. On this basis, the system RandD contents, design principle, system framework, system composition and function realization are roundly expounded. Then, the management, economic and social benefits from the system are summarized and analyzed. The power consumption management control is realized by improving of users' electricity consumption management system, developing energy-saving measures and planning energy-saving schemes through building energy efficiency management service platforms (the energy efficiency management laboratory for residential users, plants, and power supply and distribution). The system closely combines with the domestic and overseas advanced cases aiming at the energy resources and actual electrical energy consumption in China, teaching and training are carried out from three aspects, i.e., increasing the efficiency of electric equipment, optimizing electricity consumption schemes and enhancing the management and dispatching level of electric energy consumption. The electric energy efficiency management experiment system can lower energy waste and achieve the goal of green, low-carbon, balanced and sustainable development by means of providing users high-quality, standardized and efficient energy-saving technology and electric energy consumption management knowledge, prompting users to actively adopt energy consumption management control solutions as well as advanced energy-saving technology.
\end{abstract}

\section{Introduction}

Since the reform and opening-up, China's economy has developed rapidly, and the economy of China has ranked second in the world so far. In the meantime, many regions and fields have failed to handle the relationship between economy development and environment protection, the economic development is achieved at the cost of immoderately consuming resources and damaging environment, which results in more and more prominent energy and environment problems. To solve the contradiction between environment protection and economic development, the government has proposed the idea of "protecting the environment equals to protecting productivity; improving the environment equals to developing productivity", and the macro-strategy of realizing the balanced and sustainable development of China's economy by green and low-carbon development is determined .

During the "13th Five-Year Plan", China is about to complete the goal proposed in the U.S.-China Joint Announcement on Climate Change that "China intends to achieve the peak of carbon dioxide emissions around 2030 and to make best efforts to make it earlier and increase the share of non-fossil fuels in primary energy consumption to around $20 \%$ by 2030 ”. 
Moreover, the "13 th Five-Year Plan" period is a critical period for China to complete the building of a moderately prosperous society in all respects. The growth rate of China's GDP has turned into medium to high speed growth. In the new normal process, both industrialization and urbanization have entered a new development stage. The economic transition and energy transition of China are faced with a lot of difficulties. In order to properly handle the relationship between environment and social development, we must realize sustainable energy conservation and emissions reduction by means of scientific energy efficiency management.

\section{Necessity of research and development of the electric energy efficiency management experiment system}

Under the background of global energy shortage and environmental deterioration, governments around the world are attaching great importance to energy conservation and emissions reduction. To fulfill the social responsibility of energy conservation and emissions reduction and fully support the construction of the energy efficiency service system of SGCC(State Grid Corporation of China), Hubei Electric Power Company has completed the electric energy efficiency management experiment system which can realize publicity and skill experiment.

The main function of the experiment system is skill training. Its goal is improving the electric energy efficiency technology and management level of Hubei Province in all respects. The experiment system is combined with domestic and overseas advanced cases aiming at the electric energy resources and electric energy consumption in China, the teaching of electric energy management is carried out from three aspects, i.e., increasing the efficiency of electric equipment, optimizing electricity consumption schemes and enhancing the management and dispatching level.

Aiming to provide electric power users with high-quality, standardized and efficient electric energy services, according to improving electric power users' energy consumption management system, developing energy-saving measures and planning energy-saving schemes to conduct energy consumption management. The experiment system can promote the green, low-carbon and sustainable development of the society by helping electric power users to actively adopt green energy and advanced energy-saving technology and assisting local governments in realizing the goal of energy conservation and emissions reduction.

\section{Research and development contents of the electric energy efficiency management experiment system}

The experiment system carries out display and practical training of energy efficiency management for industrial users, residential users and "high-voltage power supply and low-voltage metering” power supply and distribution system users by means of developing a defined energy efficiency management control experiment platform.

Through sorting out and researching the typical application and successful experience of energy efficiency management, the experiment system provides users a series of related solutions of electric energy efficiency management.

After the integration of energy efficiency management control experiment platform and the electric energy service management platform of Hubei Electric Power Company, the remote collection, online monitoring, statistics and analysis on energy efficiency management status and equipment energy consumption status of typical electric power users can be achieved.

\section{Design of the electric energy efficiency management experiment system}

\section{Design principle of the electric energy efficiency management experiment system}

In the aspect of design, the experiment system meets the actual production and living needs and various technical indexes of electric power users, which abides by the design idea and principle of fully functional, high safety and reliability, advancement and maturity, standard and normalization. 
Advancement and practicability: Advanced design idea, equipment, technology, software system, network structure are adopted to construct the experiment system. The experiment should be in conformity with the development trend of the industry, which is easy to master and convenient to use, with the main purpose of meeting electric power users' actual energy efficiency management needs at present.

Normalization and compatibility: The experiment system follows related design, construction and technical standards issued by the state, the power sector and the electric power company.

Safety and reliability: The experimental equipment adopted by the experiment system can realize safety control at multiple levels, including the reliability of hardware equipment and the fault tolerance of software system. And its safety measures are all effective and reliable.

Opening and expandability: The experiment equipment is equipped with system interfaces and communication protocols with unified standards. The system can be compatible with similar equipment manufactured by different manufacturers.

\section{Framework of the electric energy efficiency management experiment system}

By developing a complete training platform for energy efficiency management control, the electric energy efficiency management experiment system carries out display and practical training of energy efficiency management for industrial users, residential users and power supply and distribution system users.

It mainly includes three parts: first, the application of energy efficiency management for residential users; second, the application of energy efficiency management for plants; third, the application of energy efficiency management for power supply distribution system.

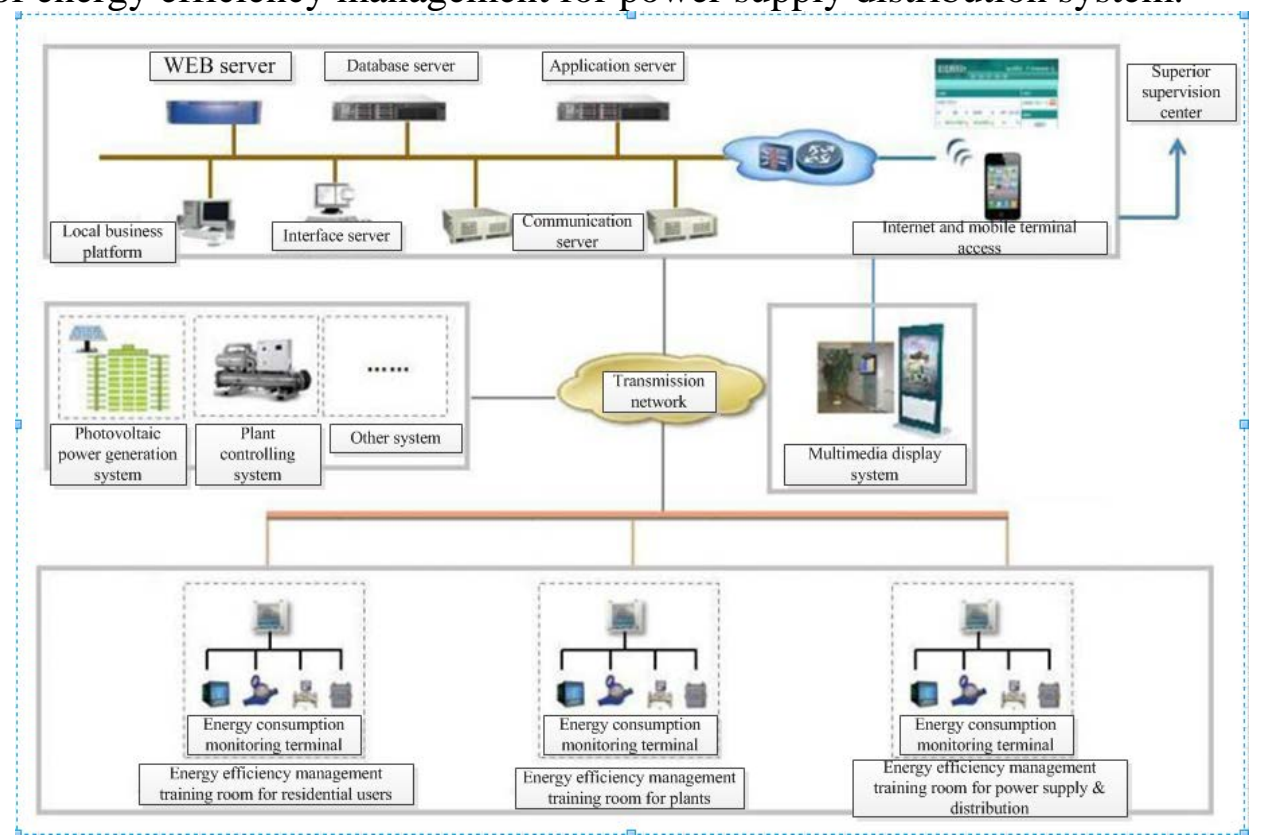

Fig. 3-1 Physical Framework Diagram of the Electric Energy Efficiency Management Experiment System

The framework of the electric energy efficiency management experiment system is divided into three layers: terminal data acquisition layer, data transmission layer, as well as the data processing and display layer.

Terminal data acquisition layer

Through the real-time acquisition of electric energy consumption data from the energy consumption terminal, and then the acquisition module encapsulate the data.

Data transmission layer

The data acquired by terminal metering device are collected into a concentrator. After receiving verification, error and exception handling, data packing and unpacking, data encryption and decryption, as well as data retransmission treatment, they may be divided into groups on the IP network and transmitted to the data center. 
Data processing and display layer

Data processing and analysis are completed in the data center. The data are received and stored and will be processed, analyzed, displayed and released. The data center is equipped with the function of setting update interval.

\section{Application framework of the electric energy efficiency management experiment system}

In the aspect of application, the experiment system is divided into five functional domains in total. Besides four business function domains, namely energy efficiency management control training, power demand side management, energy efficiency management knowledge base and report statistics, it has one system management support domain.
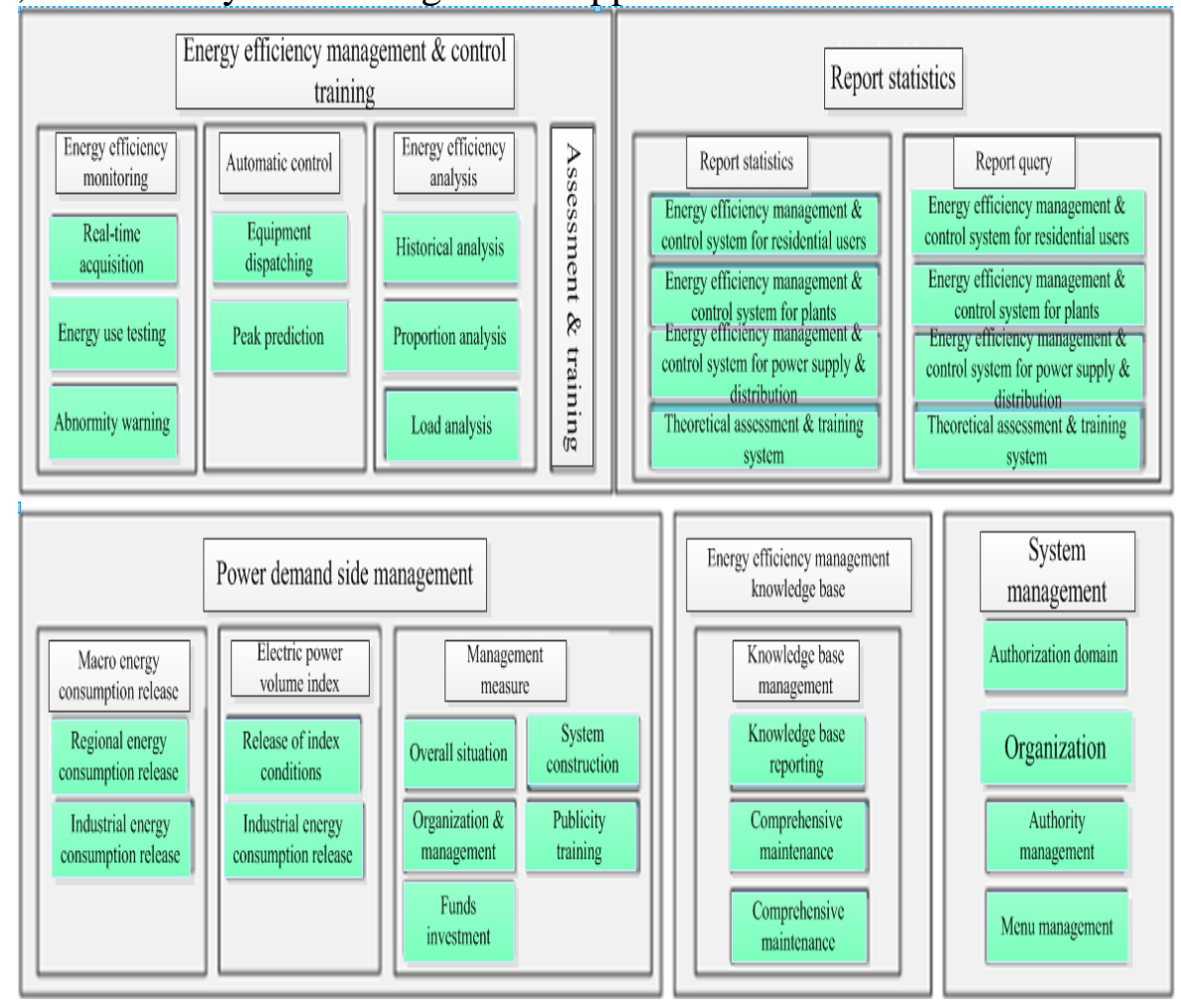

Fig. 3-2 Application Framework of the Electric Energy Efficiency Management Experiment System

\section{Composition and function realization of the electric energy efficiency management experiment system}

The experiment system is composed of three parts: the energy efficiency management laboratory for residential users, the energy efficiency management laboratory for plants, and the energy efficiency management laboratory for power supply and distribution system.

\section{Energy efficiency management laboratory for residential users}

The energy efficiency management laboratory for residential users is composed of energy efficiency management and control training platform, energy efficiency diagnosis training platform, supporting electric equipment for residential users, intelligent terminal, energy efficiency analysis and monitoring center and multimedia teaching display platform.

The energy efficiency management laboratory for residential users shows the reappearance of the residential users' electricity consumption situation with the help of a simulation training model, and provides training environment with the combination of theories and realities. The diagnosis and management control platforms monitor, analyze and diagnose the electricity consumption situation of the simulation experiment model, meanwhile control the operation mode of the electric equipment, realize the functions of training, research and practical operation assessment. The multimedia teaching equipment realizes the functions of comprehensive display teaching objectives, 
teaching methods, latest theoretical knowledge of energy efficiency management control, and successful cases of energy efficiency management.

Main functions of the energy efficiency management laboratory for residential users:

Residential users can interact with power grid terminal, including operation and overhaul information, real-time electricity price, electricity policy, electricity service information of power grid,, user's electricity consumption, residual power, electricity price, electricity balance and electricity purchase record information query.

The interactive intelligent terminal monitors the working condition of the electric equipment in real time. In case of any failure or abnormal use of the electric equipment, a warning message will be sent by sound and lighting, and the warning message will be sent to the user's phone via the Internet or mobile network information carrier so as to protect the user's personal safety and avoid family property loss.

Interactive control of household appliances. According to the residential users' requirements, the family electrical load is analyzed, and power consumption schemes are developed and optimized to guide users to reasonably use electric power. According to the requests raised by users, the energy consumption trusteeship services are carried out. The automatic management and control over the energy consumption of household appliances is realized by means of issuing the optimized operation scheme of electric equipment to family intelligent interactive terminals.

Family power consumption management. The electric power company may check the electricity information of electric equipment in real time, including electricity consumption, voltage, current and load curves. Residential users may check the information of various electricity prices at any time, including real-time electricity price and time-of-use electricity price. Through analyzing the electricity use rules of household appliances in combination with the energy consumption management system, the electric power company scientifically sets the running time of various household appliances, and provides customized electricity consumption schemes and family energy-saving suggestions for users.

\section{Energy efficiency management laboratory for plants}

The energy efficiency management laboratory for plants is composed of energy efficiency management and control training platform for plants, energy efficiency diagnosis platform, energy efficiency analysis center, frequency conversion and efficiency increase system, simulated photovoltaic power generation equipment and multimedia teaching display platform.

Through simulation training model, the energy efficiency management laboratory for plants shows the reappearance of the electricity consumption situation of plants, which provides a training environment of theory combining with the actual. The management and control training platform monitors and analyzes the electricity consumption situation, controls the operating mode of industrial equipment, and realizes the functions of training, research and practical operation assessment. In the meantime, it can comprehensively show the teaching objectives, teaching methods, latest theoretical knowledge of plant energy efficiency management control, as well as the successful cases of plants energy efficiency management.

Main functions of the energy efficiency management laboratory for plants:

(1) Theoretical training

By adopting the advanced "trend analysis" algorithm, the simulation training model of the energy efficiency management laboratory for plants can predict the load peak emerging within the measurement period and send warning message and load control signal. Besides, under the premise of ensuring production, it can regulate the electrical load in advance, not exceeding the pre-set value so as to lower the peak load power. Through increasing auxiliary controllers, the simulation training model solves the slip frequency measurement of the maximum demand. All the input and output parameters of the system can achieve online setting. For output control, the setting of the shortest turn-on time, the longest turn-on time, the shortest turn-off time and the longest turn-off time is adopted. For output channel control, priority setting can be adopted as well. The simulation training model provides real-time load power display for users to monitor the electricity consumption and 
master the change of electricity power at any time, and remote monitoring and parameter setting can be achieved via enterprise LAN.

(2) Monitoring, analysis and control on the electricity consumption situation of plants. By controlling the operating mode of industrial electric equipment, additionally arranging a reactive power compensation device while monitoring the maximum demand, adding the frequency conversion and speed regulation control system, the simulation training model of the energy efficiency management laboratory for plants fully realize the rational utilization and efficient management control of energy in the aspect of energy-saving technology and management schemes.

\section{Energy efficiency management laboratory for power supply and distribution system}

The energy efficiency management laboratory for power supply and distribution system consists of the energy efficiency management control platform, the energy efficiency diagnosis platform, the energy efficiency analysis and monitoring center and the multimedia teaching display platform.

Through the simulation training model, the energy efficiency management laboratory for power supply and distribution system shows the reappearance of the electricity consumption situation of "high-voltage power supply and low-voltage metering" power distribution system users. The simulation training model adopts inter-phase balance adjustments for "high-voltage power supply and low-voltage metering" distribution transformer, increases the output power of distribution transformer, prevents the zero-sequence current in distribution transformer, and realizes the energy consumption control of distribution transformer. Through monitoring and analyzing the energy consumption of electric equipment, the operating mode of electric equipment can be controled, and the functions of training, research and practical operation assessment can be realized. The multimedia teaching display platform achieves the functions of comprehensively displaying the teaching objectives, teaching methods, latest theoretical knowledge of energy efficiency management and control, as well as the successful cases of energy efficiency management.

\section{Energy efficiency management control training platform and other system interfaces}

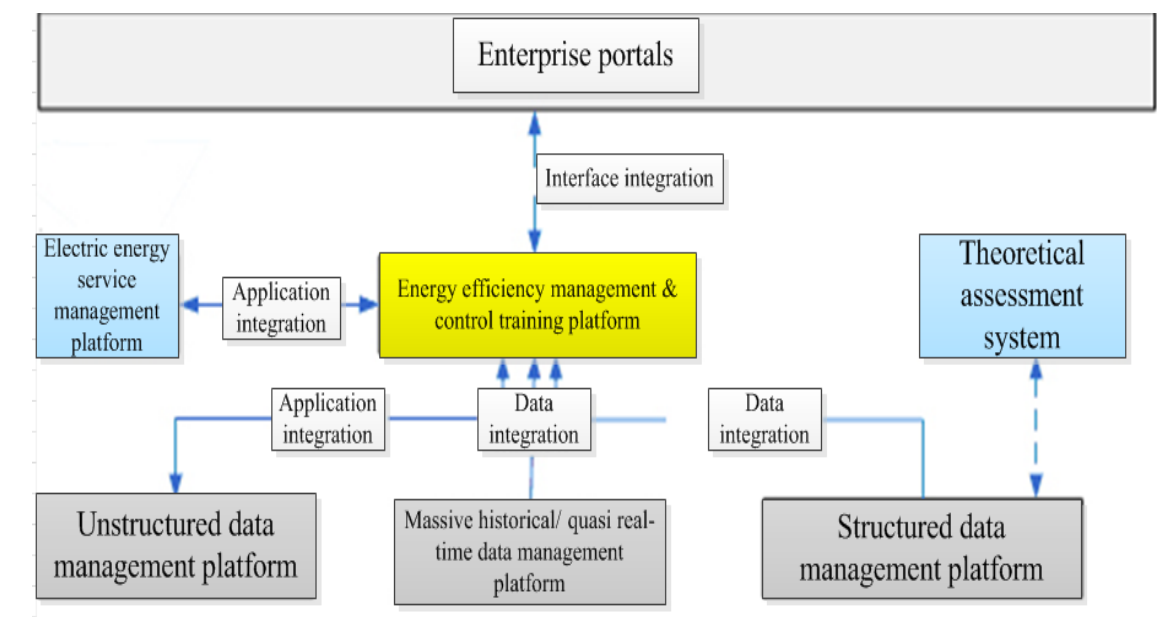

Fig. 5-1 Diagram of the Energy Efficiency Management Control Training Platform and Other System Interfaces

As shown in figure 5-1, after being connected with other systems, the energy efficiency management control training platform can achieve the following functions:

(1) Integrating with the structured data management platform, and providing massive data storage support for energy efficiency management data platform.

(2) Integrating with the unstructured data management platform, and achieving the structured data interaction.

(3) Integrating with the massive historical/ near-real-time data management platform, and achieving the efficient and massive storage of real-time data acquisition.

(4) Integrating with enterprise portals, and achieving the direct portal login. 


\section{Benefit analysis}

\section{Management benefit}

The experiment system can not only help electric power users improve the energy consumption management system and realize the goal of lowering energy consumption, but also provide a decision-making basis for the energy efficiency management personnel of the electric power company to take energy saving measures and plan energy saving schemes. By building an exchange learning environment for employees in electric power enterprises, the learning of energy consumption management knowledge and the sharing of energy consumption management experience can be achieved. In addition, electric power users are provided with scientific electric energy efficiency management schemes.

Economic benefit

The experiment system may help enterprises and home users change their energy use awareness and improve their energy use mode. When the energy efficiency management system is adopted, both enterprises and home users will achieve optimal control on electric equipment, and save their electricity expenditure. According to statistics, energy loss of industrial enterprises resulting from poor energy efficiency management accounts for over 15\% of its overall energy consumption every year. The energy efficiency management system can bring users direct economic benefits.

Social benefit

The experiment system is utilized to carry out the practical training of energy consumption management control teaching in electric power enterprises. Then, energy consumption management personnel who have completed the practical training may propagandize among the users. Through popularizing of energy-saving technology and energy consumption management knowledge, electric power users can actively adopt green energy and advanced energy-saving technology, local governments can achieve sustainable energy conservation and emissions reduction by means of scientific energy efficiency management. Thereby, all efforts above are making a contribution to completing the macro-strategy of balanced and sustainable development of China's economy.

\section{Conclusion}

The electric energy efficiency management experiment system carries out an all-around display and practical training of the energy efficiency management for enterprise users, residential users and "high-voltage power supply and low-voltage metering" power supply and distribution system by means of developing energy efficiency management control platforms (the energy efficiency management laboratory for residential users, for plants, and for power supply and distribution system). The experiment system is fully combined with domestic and overseas advanced cases. Besides, based on the actual electricity consumption situation, it carries out practical training and teaching from three aspects, namely, improving the efficiency of electric equipment, optimizing electricity consumption schemes and enhancing the management and dispatching level of electricity consumption. While achieving the goal of energy efficiency management skill training, the management, economic and social benefits of electric power enterprises are also taken into account.

\section{References}

[1] Conference Article. A Research of User-side Energy Efficiency Assessment and Monitoring System in Smart Power Grids, 25th CUS-EPSA - 2009.

[2] Zhao Bingzhen, Fan Pengzhan, Zheng Xueming, Liao Qinwu. Application of Energy Efficiency Management Technology to Residential Power Consumption [Journal Article]- Electric Power Information Technology 2011 (10)

[3] Journal Article, Study of Energy-Efficiency Management Platform for Service-oriented Architecture - Journal of University of Shanghai for Science and Technology - 2009, 31 (5). 
[4] Journal Article, Study of Energy Efficiency Management System for Service-oriented Chemical Industry - Microcomputer Application - 2009, 25 (5).

[5] Hu Min, Building the New Normal of Ecological Civilization - Comments on Xi Jinping's Thought of Ecological Civilization Construction, China Youth Daily - December 8, 2014. 